\title{
Reflections on the role of Seeding in Social Design
}

\author{
Penny Hagen \\ Digital Eskimo/Interaction Design and Work Practice \\ Lab, University of Technology Sydney \\ Sydney, Australia \\ ph@digitaleskimo.net
}

\author{
John MacFarlane \\ Digital Eskimo \\ Sydney, Australia \\ jm@digitaleskimo.net
}

\begin{abstract}
In strategies that make use of social software participation not only defines success but also defines the design. This foregrounds particular considerations during the planning and design process about participation, and how we bridge the gap between the client vision, the project and the potential community of contributors or users. This paper introduces and reflects on the notion of seeding as a construct useful for emphasising and exploring ways to promote or increase the likelihood of successful engagement. In systems that are determined by participation, it is our position that part of our role as designers is to facilitate or seed that participation and that the act of seeding (participation) becomes a core design activity. In this paper we reflect through case studies on the significance and potential for seeding content, connection and community through our design work, and on the way this has affected our approach to and understanding of the design process.
\end{abstract}

\section{Categories and Subject Descriptors}

H5.m. Information interfaces and presentation (e.g., HCI): Miscellaneous.

\section{General Terms}

Design, Experimentation, Participation.

\section{Keywords}

Seeding, participation, design research, social software, participatory design

\section{INTRODUCTION}

This paper outlines how the notion of seeding has helped us as practitioners to name and understand aspects important in our work as designers of social technologies. In strategies that make use of social software, participation not only defines success but also defines the design. This makes the relationship between designers and users - and between design and use - acutely visible. As a result our practice extends beyond constructing, building or creating to include mapping likely opportunities for engagement, and facilitating that linking or seeding of participation. More traditional perceptions of our 'design' role

OZCHI 2008, December 8-12, 2008, Cairns, QLD, Australia.

Copyright the author(s) and CHISIG.

Additional copies are available at the ACM Digital Library (http://portal.acm.org/dl.cfm) or can be ordered from

CHISIG(secretary@chisig.org)

OZCHI 2008 Proceedings ISBN: 0-9803063-4-5 might have perceived us as being responsible for handing over a product. In systems that are determined by participation however it is our position that part of our role as designers is to facilitate or seed that participation and that the act of seeding becomes a core design activity.

Figuratively, to seed something is to cause something to begin to develop or grow [1]. Traditionally viral marketing campaigns begin with a 'seed list' of emails. A solid and well-targeted seed list increases the overall number of send-ons and the chances of the campaign's success. The authors have begun to use this notion of seeding in broader terms to name the act of initiating a source of momentum, ownership, or interaction from which a community can grow (around a project).

Seeding in this context then describes the act of initiating or facilitating a generative connection with potential stakeholders and communities at an early stage of a project that feeds into the design and facilitates 'design in use'[2]. One way this can be achieved is through the co-development of content and the building of relationships that ensure a momentum and sense of ownership within the future community. In this paper we reflect on the significance and potential for seeding content, connection and community through our design work using recent and in-progress case studies, and briefly discuss the effect this has had on how we approach and perceive the design process and our role within it.

\section{BACKGROUND}

The context of the case studies and reflections presented in this paper is a commercial design agency. At Digital Eskimo we have a commitment to working on projects with an environmental, social and political focus. Many of our clients want to seize the opportunities presented by interactive and connected technologies in order to foster and engage their audiences/communities in change practices. We partner with them and work collaboratively in developing and implementing appropriate strategies.

The specific reflections in this paper are inspired by recent projects and in-progress projects undertaken with our clients that support, promote and encourage social change. These are: WWF Habitat Diaries, Guide Dogs MySpace Pilot, and Live Local experiments. All are examples of social campaigns focusing on forms of participation where seeding has played a key factor in our approach to design.

This paper also represents ongoing work by the first author into the role of seeding and design research methods. In sharing our reflections we hope to contribute to a broader discourse on extending participatory design practices into emerging community and social software domains e.g [3-8]. 


\subsection{DESIGNING SOCIAL TECHNOLOGIES}

Interactive technologies are tools and channels to amplify and share collective messages and actions. They can give a voice to groups of people who may not otherwise be heard, or indeed motivated to participate in political or social action. Digital Eskimo's social campaign work leverages off the significant opportunities presented by interactive and connected technologies to support and motivate individuals and communities to learn, play, monitor, dialogue, reflect and grow [9].

Social systems such as Friendster, Facebook, MySpace, Flickr and YouTube, as well more localised or specific community or campaigning sites not only invite an engagement with users but also depend on contributions by users to be successful. As users, we create collective messages, actions, meanings and representations of a community through these systems, and our participation in them alters them over time $[10,11]$. Furthermore, through our contribution and participation we affect the experience of others, just as their participation alters our experiences. In such a design context the relationship with, involvement of, and dependency on users, to actualise design [12], or design in use $[5,13,14]$ is acutely visible. This is both as an outcome and as element in our design process and methods.

The growing centrality of the user to the shape of the design foregrounds particular considerations about participation and how we bridge the gap between the client, the project and the potential community of contributors or users. We expand in the following section on how the notion of seeding has been useful to us in working to bridge this gap.

\section{CHALLENGES}

Participation is not a simple design objective, and it is not achieved by simply building a website that supports participation. In a social or community setting (in possible contrast to a professional setting) we cannot guarantee or direct peoples involvement. The choice to engage and the relative quality or depth of that engagement can be facilitated, but not determined.

However in community and campaign work, building or building-upon a community is core to the measurable success of the project. There is little reward in building a system in a vacuum. Therefore part of our remit must also be in connecting "the community" to the site. This often equates to a need to extend initial design briefs, which reflect a more typical or traditional product deliverly approach, to include engagement strategies.

In work on the construction of a public collective mapping tool, Disalvo et al. found that more attention needed to be paid to engaging the so called stakeholders or participants of the system, or creating the community of users [6]. They warn of falsely assuming a motivated public willing and eager to participate (ibid). In our commercial context, this translates to us as designers seeking out ways to connect the project, the client and a potentially "unknown" public [6].

One important aspect of building this connection is ownership. A goal of participatory design in community technologies is to seed a sense of ownership in the user base [4]. Ownership identifies an important crossover point between activities of design into use; it bridges the distance between the activity of design in the controlled environment of the studio, and that which takes place in the wild $[5,15]$.

The authors have found that the notion of "seeding activities" helps to make visible within the design process the importance of encouraging engagement and fostering a sense of ownership within a future community. In particular we seek to seed content, connections and community and these concepts are explored further in the following three case studies.

\subsection{WWF Habitat Diaries}

In this first case study, from 2007 , we conducted a design research project using Mobile Diaries with the aim of better understanding people's attitudes to sustainability. Over a $2 \frac{1}{2}$ week period six participants (including three families) were recruited to take part in a mobile diary study [16]. The intention was to provide a window into the lives of participants - a way for them to share with us their world and their perspectives on it with a view to informing future community tools.

We set up the Mobile Diary platforms, which in effect created a temporary community, and a momentum and connection with the participants was formed. But when the research project was finished, the participants gave back their diaries and the blogs were switched off. On reflection it is clear that during such design research projects relationships and trust are built up and investments are made that could be leveraged or continued in a range of ways. Participating in the Mobile Diary projects creates a temporary online community and a momentum around a shared issue (e.g., sustainability in our everyday life).

These participatory methods can be seen as a stepping-stone for transitioning "research participants" into active community members; the potential is created for seeding a community of stakeholders. Through such collaborative and participatory design research activities, experts on certain topics might be identified who can continue to contribute content to a site, or act as a moderator or trusted community member.

From this perspective their participation is understood implicitly as the participation of potential community members, rather than the participation of subjects, participants or even "users". Instead of recruiting primarily for research purposes, future community members are recruited for seeding momentum, energy and input, on equitable, and, if appropriate, public terms.

In addition to making strong and personal connections with potential community members, the Mobile Diary method also provides the potential for the development of seed content [16]. At times there is little visible difference between material collected as research data, and material generated for user generated sites or platforms other than the intention and framework under which it was produced. The material that people produce in the process of doing Mobile Diaries is sharable, in its subject and its format. Under the right ethical framework it is content that could be developed or evolved, used as personal stories on a website, or posted to relevant user generated content sites.

Having participants seed content is particularly significant to social technologies which take their form through user contributions. People add content, leave messages and make connections between things, and in doing so determine the shape of the platforms and our experiences of them. Enabling 
the translation or transition of research data into content could be a way for users to directly shape the design of the system.

\subsection{Guide Dogs NSW/ACT MySpace}

The following case study talks about the generation of seed content in a youth focused not-for-profit project and its role in facilitating participation. In attempting to seed interest within a "public" to engage, or to help the "community" around such a site come into existence Disalvo et al. suggest aligning the project with existing energies in the community, or investing the project with content that makes it meaningful to the target stakeholder group [6]. This was an intentional motivation for the seeding activities conducted in this project.

In an in-progress project with Guide Dogs NSW/ACT we were fortunate to be able to engage with an existing seed community. Keen students from a local school participated in fundraising activities for the organisation, and also agreed to work with us in a collaborative Design Lab and complete Mobile Diaries. This design activity had the purpose of providing insight into the lives and attitudes of young people on certain topics, and the potential to generate or guide seed content. Accordingly consent forms indicated that participation might be followed up with a request for usage on the website.

Based on our earlier project experience the generative design methods (informed by such methods as [17] [18] [19]) used in this study were conducted with the intention to seek collaboration and insights into design of future social media tools for the organisation's young supporters, as well as the content that might seed them. Certain media were generated by students through the research, and some material created during the research process became seed content for the organisation's MySpace profile. For example, as part of a fundraising and awareness project the students put on a concert at a primary school and recorded the footage; we gained consent to use the concert audio on the profile.

In another strategy to increase the level of meaningfulness in the site's content to this particular audience, we engaged two young vision-impaired bloggers on the Guide Dogs profile. To foster a connection and generate content that was relevant to young people, short biographies of the bloggers were provided to the students, who in turn submitted questions that formed the basis for the bloggers' initial blog posts.

The research project thus seeded actual content, i.e., it led to the creation of media for the Guide Dogs MySpace profile, but it also seeded community and connections by building a relationship with its participants, and helped better define the type of seed content appropriate as the project moved forward.

\subsection{Live Local Experiments}

This final case study also describes an in-progress project where we aim to bridge the gap between the client, the project and the potential community of contributors. Instead of early design research we are rather building the container and seeking ways to encourage design in use or emergent design by deliberately seeding connections within the community - outside the platform itself. Facilitating and identifying opportunities to seed participation is as core to the design process as the design and construction of the container itself.

Live Local is a project that aims to encourage sustainable living by facilitating individual narratives about neighbourhood improvement and community engagement. The aim of the Live Local website is to showcase - in a visual and accessible way an ongoing set of experiments taken on by ordinary people working to re-engage with their neighbourhoods and neighbours. The design goal to is to make it easy to join, easy to use and easy to share, and to create a place to document the things people do to make their neighbourhoods better and friendlier, and to seek inspiration from others' experiments.

The Live Local project depends significantly upon user contribution; consequently, it is important that the initial site content be strongly indicative of the type of material desired. Seed content, in other words, needs to express various conditions and expectations that will guide user submissions following launch. That initial content is thus being selected to represent a range of categories in the site taxonomy (e.g., food, energy and social), a range of geographical locations (e.g., suburban and rural) and a range of styles and complexities. To elaborate upon the latter qualities, we wish to indicate that posts to the site require neither meticulous detail nor laborious construction. Quick, concise seed examples are being created in addition to more elaborate experiments.

Some seed content is being produced through pre-launch partnerships with groups and individuals chosen for their related interests; by collaborating with existing communities we immediately generate connections and increase the chance of seeding community for our project. In addition to the creation of seed content, these partnerships serve other key purposes: they raise awareness about the project to key demographics; they provide additional sources of insight and advice into the design of the site and of its content; and they effectively create engaged users prior to an official launch.

Our own planned seeding efforts are inspired by the interventionist approach of Urban Probes [20] and are designed to foster community engagement and trigger experimentation among external audiences. For example, placing poetry-themed refrigerator magnets on utility poles to invite random creativity; and leaving inexpensive video cameras at cafés to encourage customers to meet each other and ask questions while recording. Through these "experiments" or interventions we hope to force reconsiderations of people's surroundings, generate seed content and also inspire additional participation with the website.

In our design research (like Mobile Diaries) or design activities (like Live Local experiments), a small sample of existing users or target users are recruited. In that moment a real, personal connection is made with potential community members. In the world of shared culture and social networking, where recommendations and referrals from friends are more powerful than any marketing or communication strategy, this personal connection with future community members is extremely valuable.

\subsection{Reflections in summary}

As clients increasingly move to embrace the possibilities of participation and engagement in their campaigns we have been able to reflect on related growing trends in our work. There are several themes related to seeding and the facilitation of engagement and participation that are consistent across our work that we share here for the benefit of discussion. 
- Momentum should be maintained: Downtime between seeding activities and later phases can attenuate the sense of engagement and ownership among the participants.

- Relevancy: Cementing specific relevant and meaningful connections between the project and the future community (e.g., shared personal content) can help increase relevancy

- Individual connections: The nature of social media means potential exposure to larger networks and communities can come from building strong relationships with a small number of individuals

- Partner with existing social networks: Established communities are opportunities for grassroots or more involved forms of promotion

- Lead by example: In user generated content sites seed content can be used to "set the tone" for launch and beyond

- Early content: Early design phases can generate content that informs design

- Policies for privacy in research: New standards for communication and consent need to evolve to embrace participants as public contributors

- Extending the design brief: The design process and objectives expand beyond construction and design to engagement.

\section{CONCLUSION}

The concept of design occurring in use is not a new one, but its prominence has increased greatly with the evolution of social technologies; it has thus become acutely visible in our design context. In response we expanded and evolved our role as designers in order to better facilitate and encourage use [21], and to create conditions for participation [22]. Increasingly, we need strategies to bridge the gap between client, project and community. Seeding content, community and connections is a way to bridge the distance between design in the controlled environment of the studio and the wild terrains of use.

Some significant reconsiderations in our design methods have been triggered by the changes introduced and accelerated by social technologies. Our research and design projects are now more akin to collaborative design activities, interventions, experiments, or pilots. It becomes unclear where the design stops and the community starts. Seeking opportunities to seed content, connections and communities is now central to our evolving role as designers of technology, as facilitators of experience, and creators of conditions for growth, participation and emergent design.

\section{ACKNOWLEDGMENTS}

Thank you to our generous clients, and to Dr Toni Robertson and the IDWOP Lab at UTS.

\section{REFERENCES}

1. Shorter Oxford English Dictionary. Clarendon Press (1965)

2. Henderson, A., Kyng, M.: There is no place like Home: Continuing Design in Use. In: Greenbaum, J., Kyng, M. (eds.): Design at Work. Lawrence Erlbaum Associates (1991) 219-240

3. Karasti, H., Syrjanen, A.-L.: Artful Infrastructuring in Two Cases of Community PD. Participatory Design Conference. ACM, Toronto, Canada (2004)

4. Merkel, C.B., Xiao, L., Farooq, U., Ganoe, C.H., Lee, R., Carroll, J.M., Rosson, M.B.: Participatory Design in Community Computing Contexts: Tales from the Field. Participatory Design Conference. ACM, Toronto, Canada (2004)

5. Dittrich, Y., EriksénII, S., HanssonI, C.: $P D$ in the Wild; Evolving Practices of Design in Use Participatory Design. CPSR, Malmö , Sweden, (2002)

6. DiSalvo, C., Maki, J., Martin, N.: Mapmover: a case study of design-oriented research into collective expression and constructed publics. Proceedings of the SIGCHI conference on Human factors in computing systems. ACM, San Jose, California, USA (2007)

7. Battarbee, K., Cabrera, A.B., Mattelmäki, T., Rizzo, F.: Designed for Co-designers: Workshop Call for Participation. PDC 2008 (2008)

8. Näkki, P., Virtanen, T.: Utilising social media tools in usercentred design. CHI2007 workshop: "Supporting nonprofessional users in the new media landscape. CHI 07 (2007)

9. Hagen, P., Underwood, D.: Understanding motivation and enabling action towards change. Pervasive Persuasive Technology and Environmental Sustainability Workshop held at the 6th International Conference on Pervasive Computing, Sydney (2008)

10. MayField, R.: Social Software. http://radio.weblogs.com/0114726/categories/socialNetwor $\mathrm{ks} / 2002 / 12 / 07 . \mathrm{html}$

11. Shirky, C.: Social Software and the Politics of Groups. 2003, http://www.shirky.com/writings/group politics.html

12. Dourish, P.: Where the Action Is. MIT Press (2001)

13. Greenbaum, J., Kyng, M. (eds.): Design at Work: Cooperative Design of Computer Systems. Lawrence Erlbaum Associated, New Jersey (1991)

14. Balka, E., Wagner, I.: Making things work: Dimensions of configurability as appropriation work. CSCW. ACM, Banff, Canada (2006)

15. Hutchins, E.: Cognition in the Wild. MIT (1995)

16. Hagen, P., Robertson, T., Gravina, D.: Engaging with stakeholders: Mobile Diaries for social design. DUX. ACM, Chicago, USA (2007)

17. Stappers, P.J., Sanders, E.B.-N.: Generative tools for context mapping: tuning the tools. Third International Conference on Design \& Emotion. Taylor \& Francis, Loughborough (2003)

18. Visser, F.S., Stappers, P.J., Lugt, R.V.D., Sanders, E.B.-N.: Contextmapping: experiences from practice. CoDesign 1 (2005) 119-140

19. Gaver, B., Dunne, T., Pacenti, E.: Design: Cultural Probes. Interactions (1999) 21-29

20. Paulos, E., Jenkins, T.: Urban Probes: Encountering Our Emerging Urban Atmospheres. CHI 2005, Portland, Oregon (2005)

21. Hagen, P.: Notions Of Practice; Design As Facilitation For Interactive Social Systems. FutureGround, Melbourne (2004)

22. Bødker, S.: Creating conditions for participation: Conflicts and resources in systems design. Participatory Design Conference. CPSR, Chapel Hill NC USA (1994) 